\title{
Improving HIV and STI responses through media and community engagement
}

\begin{abstract}
HIV (Human Immunodeficiency Virus) and other sexually transmitted infections (STIs) in Western Australia are at their highest in 20 years. In response to this worrying escalation and the public need for accurate and balanced information about these diseases, the journalism department at Edith Cowan University, in partnership with the WAAIDS Council (WAAC), developed a pilot project that consisted of a series of media training and education programmes to enable WAAC staff to share information and stories with the media on HIV and STIs in a more confident and proactive way. The project offers a model framework for media and community engagement that can be applied to a broader range of health promotion and disease prevention issues.
\end{abstract}

Keywords: AIDS, Australia, health communications, health promotion, HIV, media training, STIs

TREVOR CULLEN and RUTH CALLAGHAN

Edith Cowan University, Perth

\section{Introduction}

OYAL Perth Hospital Department of Immunology physician David Nolan reported in 2013 that the diagnosis rate for HIV was higher in Western Australia than it was in the 1980s and that, since 2005, there has been a steady rise. The 2013 figures were the highest on record but the diagnosis rate has since shown no sign of slowing. These increases are attributed to a number of factors, such as migration, travel, online forums facilitating sexual encounters, but also because of a rise in heterosexual men and women being diagnosed. HIV is still spreading in WA communities and needs to be addressed together with the increase in sexually transmitted infections (STIs) (Gartner, 2013).

Figures from the Australia Bureau of Statistics also show that WA has among the highest rates of chlamydia and gonorrhea in the country, second only to the Northern Territory (ABS, 2013). Youth Affairs Council Executive Officer Craig Comrie said: 'Sexual health should be as important to people in the community as mental health. The reality is the statistics show one in five 
young people experience mental health concerns. One in five young people in WA have chlamydia. One area of concern is the fly-in, fly-out workers in WA who travel to Bali during their working breaks' (Comrie, 2013) but other changes that have been linked with the rise in STIs include the use of online dating (Bateson, Weisberg, McCaffery and Luscombe (2012), and a reported decline in safe sex practices (O’Leary, 2015).

Despite the increasing spread of HIV and STIs in WA communities, media coverage of this important health issues remains patchy and sensationalist. Yet academic debate over the past 25 years shows the media has an important role to play. Ratzan (1993) argued that despite differing views on the precise role of the media in reporting HIV, there was broad agreement on the fact that the media are an important and influential source of health and medical information, and that they shape public understandings of, and responses to, the current epidemic. 'The media have enormous potential to help stop the spread of AIDS if they could inform the public continuously and accurately about the true nature and scope of HIV risks around the world' (Ratzan, 1993, p. 256). He stressed in the early 1990s that journalists should rise above the epidemic of complacency, stigma, and denial to uncover solutions for slowing HIV infection in the most devastated areas of the world. 'Effective health communication is our primary and most potent weapon in preventing the spread of AIDS. Until a vaccine or cure for HIV infection is discovered, communication is all we have' (Ratzan, 1993, p. 257).

The United Nations programme on HIV/AIDS stressed the pivotal role that media play in preventing HIV through educating people about HIV. In the UNAIDS publication, The Media and HIV/AIDS: Making a Difference, it states that without an immediate cure or vaccine, then education is the best vaccine against the disease and encourages engagement with the media (UNAIDS, 2004).

Swain (2005) argued that the media, particularly journalists, exercise a significant influence in moulding public opinions and attitudes towards the disease and that much of society's understanding of the disease, including who it affects and its future possibilities, comes from the media (Swain, 2005, p. 258). Yet, coverage of HIV in many parts of the world has been erratic and often journalists frame the epidemic as an emergency rather than a lasting concern. Also, news analysis frequently fails to recognise socio-economic contexts that made it more difficult for some to avoid infection such as poverty, disempowerment, and inequalities (Swain, 2005, p. 259).

Research on media coverage of HIV shows that if effectively used, the media can lessen the fear and stigma that are the biggest obstacles to seeking information and treatment (Cullen 2000, p209). However, there has been a disproportionate emphasis in the media on reporting HIV infection rates with little in-depth analysis of the disease or informational content (Cullen, 2000, 2006, 2010). While the language and tone of HIV stories show more sensitivity to people living with 
HIV/AIDS (PLWHA), Cullen (2014) argues there is a need to widen coverage and report HIV as a story with medical, political, social, economic, cultural, religious and relationship aspects. Engaging PLWHA to share their stories is particularly important in the delivery and clarification of health messages (Cullen \& Callaghan, 2010). This last point is supported by the Australian government's national strategy on HIV, which stresses the need to ensure the continuous involvement of PLWHA as key partners in prevention education (Australian Government Department of Health and Aging: Sixth National HIV Strategy 2010-2013).

In an attempt to foster improved and responsible media reporting on HIV and STIs which will allow for better understanding and response to these diseases, the journalism department at Edith Cowan University, in collaboration with the WAAC, developed a pilot project entitled Beyond the Red Ribbon that provided both media education and training programmes for more than 40 staff at WAAC. The project drew on the successful 'Mindframe' initiative that has resulted in significant improvements in the reporting on mental health and suicide (Mindframe, 2014).

Key to the success of this project was a partnership approach linking community and media in the development and delivery of effective health messages. Such an approach is in line with international, national and state government policy guidelines. For example, the WA government's model of care implementation from 2010-2014 endorsed a partnership approach to the overall management of HIV and highlights the importance of education and research institutions in this work. ECU's collaborative partnership with WAAC was intended to be a practical example of this policy in practice as better educated journalists, and more stories and shared experiences on HIV and STIs, should impact on the public's knowledge and response. By providing community organisations such as WAAC with the skills and knowledge necessary to produce and deliver more effective media messages, and building bridges between these grassroots groups and media organisations who deliver the messages, the project aimed to bring about improved awareness and knowledge of HIV and STIs among the public. More broadly, this partnership project also wanted to investigate and pilot a model or framework of community and media engagement which could improve awareness and responses to HIV and STIs in Western Australia that could also have broader applicability to a range of health and disease prevention issues.

\section{Methodology}

The media education programme (MEP) had two main components. The first involved engaging with WAAC staff to broaden understanding of how the media operates, and secondly, developing their skills so they competently and confidently share their stories and experiences more effectively in the media.

Phase 1: Two media education seminars with WAAC staff 


\section{Phase 2: Three media training workshops for WAAC staff}

The second phase also involved the design of a media kit, which was distributed to each participant. The content for the media kit was based on feedback gathered from face-to-face interviews with WAAC project participants and qualitative interviews with the Executive Team responsible for the delivery and implementation of the Mindframe National Media Initiative based at the Hunter Institute of Mental Health in Newcastle, NSW.

In each media training session, the group was asked to assist in defining the strengths and weaknesses as they saw them of different kinds of media engagement - both with traditional media and in their extensive practice and use of emerging or social media. This information then provided the basis for the training, to ensure examples, strategies and recommendations were targeted and related to authentic media queries or topics.

In addition, the trainers used a modified version of the continuous improvement 'plan-do-check-act' model as a framework for the training. The continuous improvement model is recognised as being useful when developing a set of processes that can be repeated or when taking an action that should be evaluated. While participants were not explicitly told this process was underpinning facilitator questions, they were taken through the steps throughout the training as they considered different media options.

As an example, participants were asked to develop some principles that might govern their media response to a controversial topic, such as what they might say to a teenager wanting needles for steroid use. This process represented the 'plan' phase of continuous improvement. Once they had discussed their media messages and strategy in relation to the topic, they were asked to articulate their positions in the same way that they would in an interview - the 'do' phase. The results of the interview were then opened to the group for discussion, allowing the interviewee to discuss how they felt about the process and the messages that they were trying to deliver. This 'check' phase was particularly useful as messages that sounded appropriate during planning could sometimes be garbled or confused when participants had to articulate them in an interview setting. Through the 'check' discussion, messages were refined and original principles were tested. Each cycle concluded with a new, improved set of messages and principles for media engagement as part of the 'act' phase, with participants made more aware of the need to develop their communication skills as circumstances changed.

\section{Specific challenges}

Five specific challenges for WAAC were identified through the training sessions, which are recorded here as they may be applicable to a number of similar or related health promotion organisations. 


\section{Challenge one: Increasing use of non-traditional media sources to reach key markets}

WAAC reported that while they still received occasional calls from mainstream media outlets, this level of contact had declined over time as the relative newsworthiness of HIV had decreased. There was also additional 'competition' in the sexual health advisory space as other groups provided media comment on STIs, transmission rates and sexual practices. While WAAC did engage in proactive contact with news media, senior members of the team found journalists were usually disinterested in stories that promoted general health information or which had an educational focus. Mainstream coverage had tended to be confined to particular events, such as its annual STYLEAID fundraising fashion event or World AIDS Day.

The organisation had recognised it needed to use non-traditional media sources to reach key markets, particularly younger people, so had developed multiple Facebook pages, a Twitter account, Instagram accounts, and a presence on Tumblr. This fragmentation of the media focus meant that more time was required to prepare messages and update each channel (which frequently had a narrow, specific audience, limiting leveraging of content). The time-consuming nature of new media engagement was a key driver in WAAC seeking media advice, as it had become impractical for external communications control to rest in the hands of a few senior team members given the number of different messages and channels WAAC now felt it needed to address.

\section{Challenge two: Diversifying of voices within an organisation that can speak to media groups.}

With the decision to devolve the communications role and empower a larger group to speak on behalf of the organisation, WAAC faced other challenges. One of these related to the number of part-time and casual or volunteer staff within the organisation. The leadership team at WAAC sought to encourage a wide group of people to be able to respond to any media queries and had empowered them to produce their own media content through non-traditional channels. Many of the team were comfortable with this approach, and some had experience in working with journalists or in publishing content in other contexts. The level of experience - and of comfort in representing the organisation-varied significantly, however.

Mock interview scenarios, in which WAAC interviewees were put through moderate to difficult questioning by the trainers in the role of a journalist, found that initial confidence in answering queries could evaporate if questions became contentious. While the sessions had been initiated with the intention of developing staff confidence in talking to the media, the mock interviews had, at times, the opposite effect. A lesson for trainers out of these sessions was that exposing staff members to challenging interviews could be counterproductive if it undermined the willingness of participants to put training into practice out of fear of making a mistake. 

An important principle of WAAC's engagement with its constituency is a commitment to providing non-judgemental advice and support. Its mission includes reducing 'social, legal and policy barriers which prevent access to health information' and in training sessions WAAC staff frequently stressed the importance of providing advice without stigmatising people or behaviour. This in turn presents a challenge for WAAC in delivering messages that address risky or unsafe practices. On a number of occasions, staff noted that they tried to balance the need to raise awareness of the dangers in, say, male sexual intercourse without condoms, with the belief that taking a critical stance on this practice could make it less likely for a person to attend a WAAC clinic for advice.

This is a critical distinction for a health promotion group such as WAAC, and distinguishes them from some other services that might, for example, be able to harness admonishing messages like 'stop smoking' or 'lose weight' that are memorable for their clarity and simplicity. Instead, WAAC's messaging tended to be nuanced or even equivocal on whether someone 'should' or 'should not' do something that carried a risk. On the one hand this meant messages were less likely to be perceived as criticism by key audiences but on the other hand allowed for misinterpretation.

\section{Challenge four: Developing messaging that fully encapsulate WAAC positions, when these positions can sometimes be deliberately flexible}

As noted earlier, the continuous improvement framework used to structure discussions around messages allowed participants in the group to focus on different scenarios and plan the messages they might choose to disseminate if asked about various topics. The option of self-testing of HIV was selected as one potential scenario for discussion, in part because its novelty increased the relative newsworthiness of the topic. At the time of the first media session, there were a number of stories that had been published by the medical community that raised concerns about self-testing, including a relatively high risk of false positive results, estimated to occur in 1 to 2 per cent of tests (RACGP, 2015). The group was asked to develop the WAAC position on self-testing, to determine what messages might be given to a journalist were they to call and ask 'Is this a good idea?' This prompted considerable discussion, with several potential positions emerging: that self-testing could be convenient; that self-testing could be an important tool in increasing awareness of HIV status; that self-testing raised the risk someone might receive a false-positive result; that self-testing was risky if someone reacted badly to a positive result delivered without the advice, support and context provided in a clinic.

Each of these positions is valid and the views were held to greater or lesser degrees by different WAAC staff. This lack of consensus highlights the difficulty 
in devolving responsibility for representing the organisation to a broad group of people who might be called on to deliver a cohesive organisational position in response to a media query.

\section{Challenge five: Measuring the effectiveness of new media outreach}

As noted, the use of non-traditional media was considered by WAAC as the best option for speaking directly to its different constituencies - many of them hard to reach through mass media publications. A Tumblr page addressed issues and topics of interest to gay, lesbian, bisexual and transgender teenagers, for example. An Instagram stream targeted travellers who were anticipating travelling overseas with the intention of having sex while a Facebook page spoke directly to men who had sex with men but who might not specifically identify as homosexual.

Given the relatively niche audiences addressed through these channels, it emerged that WAAC struggled to identify what media outreach was most effective in engaging audiences and what was not delivering an appropriate 'return' on the time or funds invested. The use of popular metrics such as 'likes' on Facebook were also not particularly useful; given the sensitive and personal nature of many of the areas, WAAC recognised there was a strong disinclination for some people who might be within a target audience to publicly acknowledge a site on sexual practices with a 'like'.

This particular challenge was not successfully resolved in the training sessions, however a number of options for better evaluation of effort were discussed. These included asking people at the point of clinic attendance what WAAC sites or channels they had seen and what messages they remembered, and greater use of analytical measures that count impressions of social content and reach rather than retweets, likes or active sharing.

\section{Outcomes to date}

The pilot project was immediately translated into policy as it had been identified as a vital component of the WAAC's revised media and communications strategy. Andrew Burry, chief executive officer of the WAAC, said the feedback from the participants had been overwhelmingly positive and appreciative. 'Learning what to do when a journalist calls, how to conduct interviews and how to maintain contacts afterwards has been really invaluable in getting essential information out to a variety of communities,' he said.

Moreover, the project will be offered to other state-based AIDS Councils throughout Australia via the Australian Federation of AIDS Organizations. The Australian Society for HIV Medicine (ASHM) asked Cullen to deliver media training workshops for 134 AIDS community leaders from 22 developing countries before and after the World AIDS Congress in Melbourne in July 2014. These 
workshops offered another opportunity to disseminate information about the project as well as gather information about how the model could be used or adapted for different contexts such as in developing nations. The project broadly addressed the national strategic research priority of promoting population health and wellbeing, helping to build resilient communities and helping Australians achieve physical, mental and social wellbeing.

More specifically, using feedback from the participants on the content and delivery of both the media education and training programme, the project:

- Improved understanding of how the media works on the part of grass roots community organisations such as WAAC;

- Improved skills on the part of grass roots community advocates such as WAAC in handling and exploiting print, broadcast and social media to disseminate their key messages. This is a pilot project, and it is the intention to offer the resources and education programs nationally to AIDS organisations throughout Australia to improve relationships with media on a national scale;

- The project has provided a framework to develop a broader model for community/media engagement that can be applied to other health and disease prevention issues;

- Improved dissemination of stories and experiences of people living with HIV/Aids and STIs which are key ingredients for effective health communications as they put a 'human face' on these diseases;

- The framework of community and media engagement which underpinned the media education program has broader applicability for other health promotion/disease prevention initiatives beyond HIV/STIs.

This last point sets the scene for another potential stage of the project-namely the training of health personnel working in other health promotion areas such as diabetes and heart disease. As a start, the plan is to approach the WA Health Department and share what was achieved with staff at the WA AIDS Council, hoping they will adopt the 'media training approach' that will incorporate lessons learnt from this pilot project.

\section{References}

Australian Bureau of Statistics (2011). Case of chlamydia and gonorrhea in Western Australia. Retrieved on August 30, 2015, from www.abs.gov.au/AUSSTATS/abs@. nsf/Lookup/4102.0Main+Features10Jun+2012

Australian Government Department of Health and Ageing (2010). Sixth national HIV strategy 2010-2013.

Bateson, D., Weisberg, E., McCaffery, K., Luscombe, G. (2012). When online becomes offline: attitudes to safer sex practices in older and younger women using an Australian internet dating service. Sexual Health, 9: 152-159.

Comrie. C. (2013). STIs on the rise in WA. Retrieved on March 1, 2015, from www.news. 
com.au/breaking-news/stds-on-rise-in-wa-call-to-make-sex-education-compulsory/ story-e6frfkp9-1226584545080

Cullen, T. (2000). Press coverage of HIV/AIDS in Papua New Guinea and the South Pacific. Unpublished PhD thesis. St Lucia, QLD: University of Queensland.

Cullen, T. (2006). HIV/AIDS: 25 years of press coverage. Australian Journalism Review. 28(2), 187-198.

Cullen, T. \& Callaghan, R. (2010). Reporting HIV in Papua New Guinea: trends and omissions from 2000 to 2010. Pacific Journalism Review, 16(2), $163-176$. Retrieved on June 2, 2015, from pjreview.aut.ac.nz/sites/default/files/articles/pdfs/ pjr16\%282\%29_reportinghiv_cullen_pp163-177.pdf

Cullen, T. (2014). Mind the gap: health reporting in the Pacific. Pacific Journalism Review, 20(2), 200-212. Retrieved on June 2, 2015, frompjreview.aut.ac.nz/sites/default/files/ articles/pdfs/PJR201May2014-MindTheGap-cullen-pp200-212.pdf

Gartner, A. (2013). HIV diagnosis on the rise again in Perth. Retrieved on September 1, 2013, from www.inmycommunity.com.au/news-and-views/local-news/HIV-diagnosison-the-rise-again/7642704/

O'Leary, C. (2015). HIV rise points to safe decline. Retrieved on June 2, 2015, from https://au.news.yahoo.com/thewest/wa/a/26086041/hiv-rise-points-to-safe-sex-decline/

Mindframe National Media Initiative Resources (2014). Retrieved on September 14, 2014, from www.himh.org.au/home/our-resources/mindframe-resources

RACGP (2015). At home HIV test kits risk false results, says peak body for general practice. Racgp.org.au. Retrieved June 18, 2015, from www.racgp.org.au/yourracgp/ news/media-releases/hiv-test-kits/

Ratzan, S. (Ed.) (1993). AIDS: effective health communication for the 90s, Boston, MA: Taylor and Francis.

Swain, K. (2005). Approaching the quarter-century mark: AIDS coverage and research decline as infection spreads. Critical Studies in Media Communications, 22(3), 258-262

UNAIDS (2004). The media and HIV/AIDS: Making a difference. New York: UNAIDS

Western Australian Government Department of Health Department (2010). HIV Model of care implementation plan 2010-2014. Retrieved on March 14, 2015, from www.health.gov. au/internet/main/publishing.nsf/Content/ohp-national-strategies-2010-hiv/\$File/hiv.pdf

Wilson, A. (2012). Bad medical reporting: a history of shooting the messenger. Retrieved on May 7, 2015, from http://theconversation.com/bad-medical-reporting-a-historyof-shooting-the-messenger-67

DrTrevor Cullen is associate professor of journalism and programme director at Edith Cowan University, Perth, Western Australia. His doctoral thesis focused on press coverage of HIV/AIDS and since then he has written numerous peer-reviewed articles and run workshops in the Asia-Pacific region on the topic, and has researched widely on health issues. An earlier version of this article was delivered at the Pacific Journalism Review twentieth anniversary conference at AUT University, Auckland, in November 2014. t.cullen@ecu.edu.au

Ruth Callaghan is a lecturer in journalism at Edith Cowan University, Perth, where this article was prepared and delivered. 